\title{
Common factors versus uncommon variability in comparisons of the Poggendorff and Müller-Lyer illusions
}

\author{
H. R. SCHIFFMAN \\ Rutgers University, New Brunswick, New Jersey \\ and \\ SUZANNE GREIST-BOUSQUET \\ Kean College, Union, New Jersey
}

\begin{abstract}
Evidence for a common contributing factor in the Müller-Lyer and Poggendorff illusions is reviewed and complemented by correlational studies of the two illusions. However, these findings are compromised by consistent differences in the variability of the two illusory effects. In general, the variability associated with judgments of linear extent is consistently greater than the variability associated with alignment judgments. These findings were obtained with different figures, different stimulus parameters, and different response procedures. The difference in variability suggests problems for the notion of a common causal factor in illusions of linear extent and of direction.
\end{abstract}

Most visual illusions, typically seen as simple twodimensional line drawings, consist of discrepancies between perception and physical reality. However, such illusions do not result from mere random variations in perception or occasional misperceptions; rather, they are part of the consistent output of ongoing perceptual processes and mechanisms invoked in the perception of space. It follows that, as consistent misperceptions, the occurrence of visual illusions may serve as a tool for the discovery of general processes and mechanisms of perception.

Since illusory figures were first described in the 19th century (by Oppel in 1854, according to Coren \& Girgus, 1978), several hundred of them have been catalogued (Coren \& Girgus, 1978; Luckiesh, 1922/1965; Robinson, 1972; Tolansky, 1964). For the most part, attempts to uncover a single specific or even dominant causal factor of most visual illusions have been unsuccessful. It appears that even structurally simple visual illusions (e.g., the horizontal- vertical illusion) are the result of several factors (see Masin \& Vidotto, 1983). Since single-factor explanations are not sufficient to explain most visual illusions, it is reasonable to assume that visual illusions result from a number of interacting effects. Indeed, Coren and Girgus (1978) have formalized this notion and have proposed that many visual illusions result from the contribution of several factors, arising at different levels in the perceptual process, with each making a separate contribution toward effecting a consistent misperception. An appealing aspect of this multicausal approach is that it in-

Correspondence should be addressed to S. Greist-Bousquet, Department of Psychology, Kean College, Union, NJ 07083. vites the dissection and analysis of visual illusions into discrete components. Through the isolation and identification of the various underlying contributing factors of a number of apparently different illusions, it may be possible to discover common factors. Thus, although a singlefactor explanation of most visual illusions cannot be made, common contributing factors may be identified for seemingly different illusions.

Some specific evidence for a common contributing factor in the Müller-Lyer and Poggendorff illusions has been reported by Greist-Bousquet and Schiffman (1981a, 1985). In the standard Poggendorff illusion, the two collinear oblique lines, or transversals, appear to be misaligned. Several investigators (e.g., Pressey, 1971; QuinaHolland, 1977; Zanuttini, 1976) have suggested that this misalignment is due to an underestimation of the distance between the parallels. Figure 1 illustrates how underestimation of interior extent may promote misalignment.

Greist-Bousquet and Schiffman (1981a) verified empirically the intertransversal underestimation, and suggested that the underestimation might be due to the influence of an amputated form of the wings-in Müller-Lyer figure contained within the Poggendorff parallels (Figure 2B). Other investigators have also found underestimation of inner oblique extent when subjects produce (Weintraub \& Tong, 1974), adjust (Judd, 1899), or compare (QuinaHolland, 1977) stimuli that are equivalent in content and orientation (i.e., unfilled oblique extent). Although an analogous wings-out figure is also present in the Poggendorff parallels (Figure 2C), other previous research on the Müller-Lyer illusion (e.g., Greist-Bousquet \& Schiffman, 1981b; Warren \& Bashford, 1977) has indicated that this amputated variation produces little overestimation. 
B

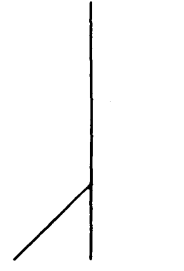

A
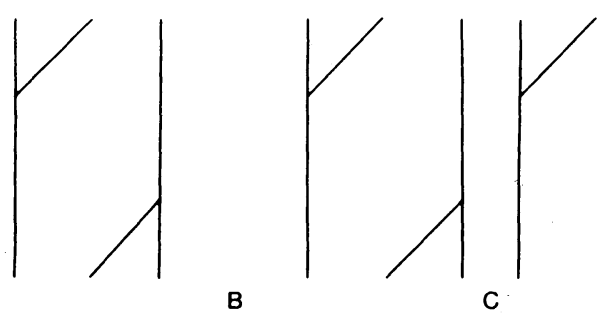

Figure 1. The classic Poggendorf illusion (A) may be attributable to an underestimation of the distance between the parallels. As the right parallel is moved laterally, the increase in interior extent produces the impression of subjective collinearity (B), whereas a decrease in interior extent accentuates the misalignment effect (C).

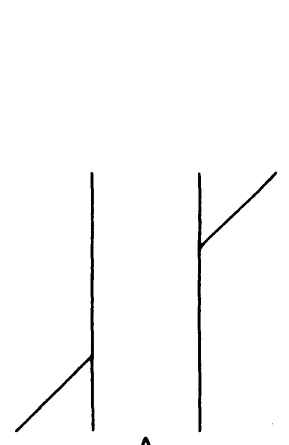

A
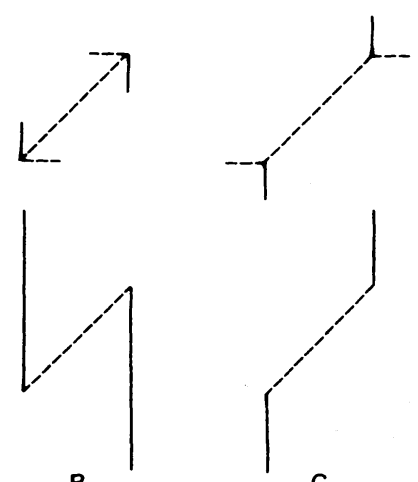

C
Figure 2. The Poggendorff figure (A) contains an amputated version of the wings-in Müller-Lyer illusion (B) and an amputated version of the wings-out Müller-Lyer illusion (C). (The complete MüllerLyer figure is shown above $B$ and $C$ ).

The specific evidence for the relationship between the Poggendorff and Müller-Lyer illusions is briefly the following: Poggendorff underestimation is a function of the number and type of parallel components in the Poggendorff figure (Greist-Bousquet \& Schiffman, 1981a). Poggendorff misalignment is a function of the length of the parallel components, distance between the transversals, and angle between the transversal and the parallel components (Greist-Bousquet \& Schiffman, 1985). These Poggendorff functions correspond to analogous research on the Müller-Lyer illusion which shows that wings-in Müller-Lyer underestimation is a function of the number of wings (Warren \& Bashford, 1977), the length of the wings, the distance between the wings, and the angle of the wings (e.g., Restle \& Decker, 1977).

In addition to the parametric studies noted above, a correlational study has shown that there is a significant relationship between alignment and extent estimates in variations of the Poggendorff illusion (Greist-Bousquet, Schiffman, Dorsett, \& Davis, 1989). A more direct evaluation of the relationship between the Poggendorff and Müller-Lyer illusions in our laboratory has revealed a significant positive correlation between alignment judgments in the standard Poggendorff illusion and distance judgments in the wings-in Müller-Lyer illusion $[r(31)=0.4821, p<$ $.0027]$. In the same study, we found no significant correlation between the standard Poggendorff illusion and the wings-out Müller-Lyer illusion [ $r(31)=-0.1600, p>$ $.05]$. Thus, a more direct examination of the relationship between the two illusions provides support for the notion of a common causal component for the Poggendorff and wings-in Müller-Lyer illusions.

Despite this research on the relationship between the Poggendorff and Müller-Lyer illusions and controversy regarding a common causal basis in these illusions (e.g., Day, Jolly, \& Duffy, 1987; Trueman \& Wilson, 1989), it must be stressed here that we have consistently encountered differences in the variability of the two illusory effects. In the correlational study noted above, the variability in the responses to the wings-in and wings-out MüllerLyer figures was substantially greater than the variability observed for Poggendorff alignment judgments (see Table 1). Furthermore, in five separate studies in our laboratory concerning the relationship between intertransversal extent judgments and alignment judgments in the Poggendorff illusion, we have found that the variability associated with extent judgments is consistently greater than the variability associated with alignment judgments. This finding was obtained with different figures (upright vs. diagonally oriented Poggendorff figures), different stimulus parameters (parallel lengths, transversal lengths, and intertransversal extents), and different response procedures (method of reproduction and method of adjustment). A within-subjects design was used in each study, so that differences in variability cannot be attributed merely to differences between groups. Table 2 summarizes these findings.

Thus, the attempt to identify a common contributing factor in the Müller-Lyer and Poggendorff illusions to make the catalog of illusions more manageable is undermined by differences in illusion response variability. Indeed, the differences in variability suggest that perhaps very different processes may be in effect when subjects make extent and alignment judgments. In addition, the present report casts doubt on other specific examinations of the relationship between judgments of intertransversal extent and tranversal alignment in the Poggendorff illusion (e.g., Trueman \& Wilson, 1989) when variability is not reported. In general, the overall findings on variability differences in the two illusions makes the notion of a common causal factor problematic. At the least, it appears that caution should be exercised in the examina-

Table 1

Judgments of Poggendorff and Müller-Lyer Musions (in Millimeters)

\begin{tabular}{lcc}
\hline & $M$ & $S D$ \\
\hline Poggendorff alignment* & 58.11 & 2.79 \\
Wings-in Müller-Lyer & 56.45 & 5.42 \\
Wings-out Müller-Lyer & 62.70 & 7.26 \\
\hline
\end{tabular}

Note-Müller-Lyer extent and Poggendorff intertransversal extent were $60 \mathrm{~mm}$. *Converted to intertransversal extent (see Weintraub \& Krantz, 1971). 
Table 2

Results of Studies of the Relationship Between Poggendorff Alignment and Intertransversal Extent

\begin{tabular}{|c|c|c|c|c|c|c|}
\hline \multirow[b]{2}{*}{ Figure Type } & \multirow[b]{2}{*}{ Stimulus Specifications } & \multirow[b]{2}{*}{ Subject Task } & \multicolumn{2}{|c|}{ Extent } & \multicolumn{2}{|c|}{ Alignment } \\
\hline & & & $M$ & $S D$ & $M$ & $S D$ \\
\hline Vertical parallels & $\begin{array}{l}\text { Parallel length } 215 \mathrm{~mm} \\
\text { Transversal length } 47.5 \mathrm{~mm} \\
\text { Intertransversal extent } 85 \mathrm{~mm}\end{array}$ & $\begin{array}{l}\text { Recreate extent } \\
\text { Produce aligned dot }\end{array}$ & 76.79 & 6.53 & 79.85 & 5.32 \\
\hline Diagonal parallels & $\begin{array}{l}\text { Parallel length } 80 \mathrm{~mm} \\
\text { Transversal length } 10 \mathrm{~mm} \\
\text { Intertransversal extent } 22 \mathrm{~mm}\end{array}$ & $\begin{array}{l}\text { Recreate extent } \\
\text { Produce aligned dot }\end{array}$ & 20.07 & 3.79 & 21.02 & 0.97 \\
\hline Diagonal parallels & $\begin{array}{l}\text { Parallel length } 80 \mathrm{~mm} \\
\text { Transversal length } 10 \mathrm{~mm} \\
\text { Intertransversal extent } 22 \mathrm{~mm}\end{array}$ & $\begin{array}{l}\text { Recreate extent } \\
\text { Produce aligned dot }\end{array}$ & 20.44 & 2.60 & 21.12 & 1.27 \\
\hline Diagonal parallels & $\begin{array}{l}\text { Parallel length } 80 \mathrm{~mm} \\
\text { Transversal length } 10 \mathrm{~mm} \\
\text { Intertransversal extents: } \\
17.5 \mathrm{~mm} \\
35 \mathrm{~mm} \\
70 \mathrm{~mm}\end{array}$ & $\begin{array}{l}\text { Recreate extent } \\
\text { Produce aligned dot }\end{array}$ & $\begin{array}{l}15.74 \\
32.61 \\
65.76\end{array}$ & $\begin{array}{l}2.5 \\
4.35 \\
7.83\end{array}$ & $\begin{array}{l}16.83 \\
33.08 \\
64.58\end{array}$ & $\begin{array}{l}1.03 \\
2.23 \\
8.98\end{array}$ \\
\hline Diagonal parallels & $\begin{array}{l}\text { Parallel length } 80 \mathrm{~mm} \\
\text { Transversal length } 10 \mathrm{~mm} \\
\text { Intertransversal extent } 17.5 \mathrm{~mm}\end{array}$ & $\begin{array}{l}\text { Adjust extent } \\
\text { Align transversals }\end{array}$ & 18.21 & 2.53 & 15.90 & 0.76 \\
\hline
\end{tabular}

Note-All measures of alignment were transformed into measures of intertransversal extent (see Weintraub \& Krantz, 1971). All values are in millimeters.

tion of the relationship between illusions of linear extent and illusions of direction: Although a common factor may contribute to the Poggendorff and Müller-Lyer illusions, the search for corroborating evidence is compromised by differences in the variability of subjects' responses to each illusion. Clearly, further examination of this variability, along.with a concern with the mechanisms and processes that promote the resultant variability in judgments of such figures, is in order.

\section{REFERENCES}

Coren, S., \& GrRgus, J. (1978). Seeing is deceiving: The psychology of visual illusions. Hillsdale, NJ: Erlbaum.

DAY, R. H., Jolly, W. J., \& DufFY, F. M. (1987). No evidence for apparent extent between parallels as the basis of the Poggendorff effect. Perception \& Psychophysics, 42, 561-568.

Greist-Bousquet, S., \& Schiffman, H. R. (1981a). The Poggendorff illusion: An illusion of linear extent? Perception, 10, 155-164.

Greist-BousQueT, S., \& SCHIFFMAN, H. R. (1981b). The role of structural components in the Mueller-Lyer illusion. Perception \& Psychophysics, 30, 505-511.

Greist-Bousquet, S., \& SChiffman, H. R. (1985). Poggendorff and Müller-Lyer illusions: Common effects? Perception, 14, 427-447.

Greist-Bousquet, S., Schiffman, H. R., Dorsett, R., \& Davis, J. (1989). The relation between apparent extent and alignment in the Poggendorff illusion: A response to "No evidence for apparent extent between parallels as the basis of the Poggendorff effect," by Day, Jolly, and Duffy. Perception \& Psychophysics, 46, 501-504.

JudD, C. H. (1899). A study of geometrical illusions. Psychological Review, 6, 241-261.
LUCKIESH, M. (1965). Visual illusions: Their causes, characteristics and applications. New York: Dover. (Original work published 1922)

Masin, S. C., \& Vidotto, G. (1983). A magnitude estimation study of the inverted-T illusion. Perception \& Psychophysics, 33, 582-584.

Pressey, A. W. (1971). An extension of assimilation theory to illusions of size, area, and direction. Perception \& Psychophysics, 9, 172-176.

Quina-Holland, K. (1977). Spatial distortions within the Poggendorff figure and its variants: A parametric analysis. Perception \& Psychophysics, 21, 118-124.

Restle, F., \& DeCker, J. (1977). Size of the Mueller-Lyer illusion as a function of its dimensions: Theory and data. Perception \& Psychophysics, 21, 489-503.

Robinson, J. O. (1972). The psychology of visual illusions. London: Hutchinson.

Tolansky, S. (1964). Optical illusions. New York: Pergamon.

Trueman, M. T., \& WiLson, A. E. (1989). Examination of apparent extent as an explanation of the Poggendorff effect. Perception \& Psychophysics, 45, 494-500.

WARREN, R. M., \& BASHFoRD, J. A. (1977). Müller-Lyer illusions: Their origin in processes facilitating object recognition. Perception, 6, 615-626.

Weintraub, D. J., \& Krantz, D. H. (1971). The Poggendorff illusion: Amputations, rotations, and other perturbations. Perception \& Psychophysics, 10, 257-264.

Weintraub, D. J., \& Tong, L. (1974). Assessing Poggendorff effects via collinearity, perpendicularity, parallelism, and Oppel (distance) experiments. Perception \& Psychophysics, 16, 213-221.

ZanUtrini, L. (1976). A new explanation for the Poggendorff illusion. Perception \& Psychophysics, 20, 29-32.

(Manuscript received June 26, 1993.) 